International Journal of
Processing and $7 \mid$ Issue 1 | June, 2016 | 126-133

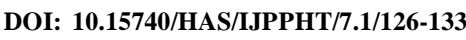

\title{
Quality evaluation of food by thermal imaging
}

\author{
- Payel Ghosh*, Sandeep Singh Rana, Ankita NayaK and Rama Chandra Pradhan \\ ${ }^{1}$ Department of Food Process Engineering, National Institute of Technology, ROURKELA (ODISHA) INDIA \\ Email: payelghosh89@gmail.com; srana0505@gmail.com; 113ft0315@nitrkl.ac.in; pradhanrc@gmail.com
}

*Author for Correspondence

Research chronicle : Received : 07.12.2015; Revised : 11.05.2016; Accepted : 23.05.2016

SUMMARY :

Temperature estimation is an imperative wonder in all mechanical and agrarian divisions. A few instruments and techniques have been produced to quantify the temperature of items. Temperature estimations in the agrarian and sustenance commercial enterprises have for the most part depended on ordinary contact techniques, for example, thermocouples, thermometers, and thermistors, which give constrained data. Non-contact strategies and temperature mapping procedures are getting to be prominent because of higher transient and spatial resolutions. A few strategies, for example, $\mathrm{x}$ beam tomography, infrared thermography, electrical impedance tomography, ultrasound imaging, microwave radiometry, and attractive reverberation imaging (MRI) are accessible to outline temperatures of organic materials. On the other hand, infrared thermal imaging has incredible potential for both pre-collect and post-harvest operations in horticulture because of the convey ability of the hardware and basic operational strategy. The decreases in expense of the hardware and basic operational method have made open doors for the application in a few fields of the agrarian and nourishment commercial enterprises. This innovation can be utilized as a part of every farming material and procedures, where warmth is created or lost in space and time. Little varieties (beneath $1^{\circ} \mathrm{C}$ ) can likewise be effectively measured with appropriate gear and system. On the off chance that the temperature distinction is too little, a suitable domain ought to be made, for example, expanding or diminishing the temperature of the specimen and measuring the rate of cooling or warming. Detection of bruise and maturity level of fruits and vegetables, overall quality evaluation can be done by the help of thermal imaging.

KEY WORDS : Fruits, Thermal imaging, Quality

How to cite this paper : Ghosh, Payel, Rana, Sandeep Singh, Nayak, Ankita and Pradhan, Rama Chandra (2016). Quality evaluation of food by thermal imaging. Internat. J. Proc. \& Post Harvest Technol., 7 (1) : 126133. DOI: 10.15740/HAS/IJPPHT/7.1/126-133 